\title{
Posibles efectos del CAMBio ClimÁtico GLOBAL EN ZONAS SILVESTRES PROTEGIDAS DE LA ZONA ANDINA DE ECUADOR
}

\author{
Possible effects of Global Climate Change in Wild Protected areas of the Andean \\ ZONE OF ECUADOR
}

Patricio Yánez M. ${ }^{1,2}$, Marlon Núñez ${ }^{3}$, Fernanda Carrera ${ }^{2}$ y Christian Martínez ${ }^{4}$

${ }^{1}$ Centro de Investigación y Modelamiento Ambiental CIMA, Universidad Politécnica Salesiana. Telf.: 593-91359249.

${ }^{2}$ Instituto de Investigaciones Científicas y Tecnológicas de la Universidad Iberoamericana del Ecuador.

${ }^{3}$ Rainforest Alliance, Hidalgo de Pinto 805 y Mariano Echeverría, Quito. mnunez@ra.org Telf.2664152

${ }^{4}$ Programa de Maestría en Biodiversidad, convenio Universidad Central del Ecuador y Universidad Internacional Menéndez Pelayo de España. Quito.

Autor para correspondencia: ayanez@ups.edu.ec

Manuscrito recibido el 10 de octubre de 2011. Aceptado, tras revisión el 15 de diciembre de 2011.

\section{Resumen}

En Ecuador se han promulgado últimamente leyes y directrices tendientes a la mitigación de los efectos del cambio climático global; sin embargo, se evidencian pocos hechos concretos sobre estas medidas, o si se las realizan no se divulgan de manera adecuada. La presente investigación analiza el potencial impacto del cambio climático en las formaciones vegetales presentes en las áreas protegidas de la zona Andina de Ecuador. Se desarrolló analizando información sobre estas áreas, su problemática, la superficie de sus formaciones vegetales, procesos de deforestación, dinámica de la tenencia de la tierra y acciones emprendidas frente al cambio climático; se elaboraron dos mapas de formaciones vegetales nativas de la Zona Andina (1999 y 2010). En una Fase posterior se proyectó la ocupación de tales formaciones bajo los supuestos climáticos previstos para 2020, según el modelo HadCM3, bajo el escenario A2 siguiendo el esquema de la dispersión máxima ajustada, atendiendo a esto se elaboró un tercer mapa de estas formaciones para el futuro próximo (2020). Se presentan Tablas con información de la cobertura de las formaciones vegetales (1999, 2010, 2020 y un cuarto con los cambios de los valores de superficie de cada formación). El presente trabajo colabora con un novel espacio en el que se aborda el conocimiento y la reflexión sobre la temática de cambio climático y sus probables impactos sobre ecosistemas de áreas protegidas, de manera que se pueda generar información documentada para la toma de decisiones de política y planificación territorial.

Palabras claves: cambio climático global, efecto invernadero, formaciones vegetales nativas, áreas protegidas andinas de Ecuador.

\begin{abstract}
In Ecuador there are laws and efforts in order to mitigate the effects of the global climate change; however, just a few facts of these measures are evident. This work analyzes the potential impact of climate change on native vegetation in protected areas of the andean zone in Ecuador. It was conducted analyzing information about these Areas, their problems, their vegetation types, deforestation processes, land tenure and actions in response to climate change; two maps were designed showing native vegetational zones of the andean zone (1999 and 2010). In the next phase, a third map was made under the climate scenario provided for 2020, according to the HadCM3 model under scenario A2 using the scheme of adjusted maximum dispersion. We also designed four tables with vegetation covers of the Andean zone: the first for 1999 information, a second one for 2010, a third one for 2020 and a final one comparing the surfaces changes. This work aims to promote the knowledge and analysis of climate change in Ecuador and their potential impacts on protected areas and their ecosystems in order to generate scientific information useful to decision makers and land use planners.
\end{abstract}

Keywords: global climate change, greenhouse effect, native ecosystems, andean protected areas of Ecuador.

Forma sugerida de citar:

Yánez, P., M. Núñez, F. Carrera, y C. Martínez. 2011. Posibles efectos del cambio climático global en zonas silvestres protegidas de la zona andina de Ecuador. La Granja. Vol. 13(1): 24-44. ISSN: 1390-3799. 


\section{Introducción}

Ecuador, al igual que otros países neotropicales, no está libre de la problemática climática actual. Esta circunstancia plantea diversas interrogantes por el hecho de afectar a nuestra vida cotidiana.

En los últimos años se ha evidenciado la vulnerabilidad del Ecuador ante cualquier modificación en los patrones climáticos, debido a que un porcentaje importante de su economía y fuerza laboral depende de actividades primarias sensibles al clima, tales como la agricultura, la pesca y el uso de sus recursos naturales. A esto se suman diferentes características de los hábitats locales que incrementan la vulnerabilidad, tales como la presión demográfica, el crecimiento urbano sin planificación, la pobreza, la inequidad y migración rural, la baja inversión en infraestructura y servicios, la degradación de tierras o su deforestación, la contaminación y sobrexplotación de recursos naturales y los problemas de coordinación intersectoriales y capacidad limitada de las instituciones (Secretaría General de la Comunidad Andina, 2008).

El cambio en los patrones climáticos, sumado a acciones antropogénicas tales como deforestación, quemas y aumento de la población, han incidido en todos los ecosistemas, mayoritariamente en la Zona Andina en la que se concentra la mayor diversidad florística, con un $64 \%$ del total de plantas registradas para el país (MAE - Ministerio del Ambiente del Ecuador, 2008). Esta riqueza, se atribuye a la diversidad de climas, al gran rango altitudinal debido a Los Andes, a los diferentes tipos de suelo, al efecto de los vientos que chocan con los flancos occidentales y orientales de las cordilleras andinas respectivamente y a la complejidad geomorfológica de Ecuador. Esta multiplicidad de factores ha dado origen a la variedad de tipos de vegetación y ecosistemas característicos.

La aplicación de modelos de idoneidad ha sido utilizada en la evaluación de los impactos del cambio climático en la distribución de la diversidad florística, mediante el uso de técnicas que usan información de las condiciones ambientales y los sitios de presencia o las áreas de ocupación potencial de un organismo; por tanto, el área potencial de éste agrupará a aquellos sitios que se muestran más adecuados o idóneos, según sus propias características ambientales. Si se cuenta con estimaciones futuras de las condiciones ambientales es posible proyectar los modelos y así evaluar las modificaciones de las zonas potenciales, bajo diversos escenarios.
Un escenario es una descripción, basada en principios científicos de una situación futura. Para construir un escenario se realizan supuestos sobre factores que pueden originar una situación. Los escenarios de emisiones de gases de efecto invernadero (GEI) son representaciones de las futuras emisiones de GEI basadas en supuestos sobre factores relacionados con su producción. Los datos se ingresan en un modelo climático para obtener proyecciones sobre el clima futuro, dentro de 20 años o más (MAE - Ministerio del Ambiente del Ecuador, 2010). La presente investigación plantea el estudio de los potenciales efectos del cambio climático en la distribución espacial de las formaciones vegetales de zonas silvestres andinas del Ecuador, específicamente en áreas protegidas. Para ello en la primera fase se realizó el diagnóstico de la situación actual de las mismas mediante la revisión de informes, publicaciones y planes de manejo, que abordan su problemática, la superficie de las formaciones vegetales, la deforestación, la tenencia de la tierra y las acciones del personal encargado de tales Áreas frente al Cambio Climático. Se generaron dos mapas de la cobertura de las formaciones vegetales (uno con datos de 1999 y otro con datos de 2010) y sobre esta base, en la fase dos, se elaboró un mapa y tablas de las formaciones vegetales de las áreas protegidas con el modelamiento de idoneidad para el año 2020, utilizando condiciones climáticas definidas por el modelo HadCM3 bajo el escenario A2 siguiendo el esquema de la dispersión máxima ajustada.

Las predicciones de cambio climático ocasionarían una reorganización espacial de las formaciones vegetales asumiendo que éstas tuviesen cierta capacidad de desplazamiento (Yánez, 2009). Los patrones de ocupación serían variables dependiendo del período de análisis, por ejemplo, (Martínez, 2009-2010) menciona lo crítico que sería el escenario A2, considerando una capacidad de dispersión máxima ajustada, en el que la pérdida de cobertura vegetal sería del $23 \%$ en la Zona Andina.

Según Cáceres (2001), el impacto del cambio climático causaría una tendencia a la desertificación en la Región interandina. Los cambios de las temperaturas mínimas y máximas absolutas tenderían a ser cada vez más extremos por lo que incidirían notablemente en la estabilidad de las formaciones vegetales andinas (Cáceres et al., 1998).

Según estudios similares (Delgado, 2008) en la región interandina alta, es previsible que converjan plantas de ambas vertientes de los Andes, creándose posiblemente nuevas combinaciones de especies y, por con- 
siguiente, nuevos ecosistemas.

En cuanto a la deforestación, si bien existen deficiencias de información y una alta dispersión de las fuentes, es indiscutible que ésta constituye uno de los problemas de mayor impacto sobre las áreas protegidas. Oficialmente, el Ecuador reporta para la última década una pérdida de cobertura natural de 137.000 ha/año (ECOLAP y MAE, 2007).

Las variaciones de temperatura, distribución temporal y espacial de las precipitaciones, el retroceso de los glaciares, desfases de épocas de lluvia, inundaciones, sequías, olas de calor, de frío, etc., que sucedan en cualquier ecosistema o formación vegetal, provocarían impactos ambientales, económicos y sociales que posiblemente se intensifiquen sobre los elementos básicos para la vida, como acceso al suministro de agua, producción de alimentos, salud, etcétera. (INAMHI, 2009).

Existe una gran preocupación por las tendencias actuales del cambio climático en el Neotrópico, que indican un aumento en la temperatura atmosférica como resultado del aumento de los GEI (Jiménez et al., 2009). Por eso es importante generar nuevos conocimientos a nivel local para enfrentar su impacto, como en el presente estudio sobre la cobertura vegetal natural.

Considerando dichas tendencias, este estudio analizó el impacto del cambio climático a nivel de formaciones vegetales nativas de la zona andina de Ecuador. Utilizando el enfoque de desplazamiento gradual de las mismas (Yánez, 2009), según el escenario A2 y con especial énfasis en los territorios de las actuales áreas protegidas; las proyecciones se hicieron hacia el año 2020 para visualizar los patrones espaciales y temporales del cambio; el esquema propuesto es válido bajo los supuestos de homogeneidad en el interior de cada formación vegetal y de que su representatividad actual es suficiente para caracterizar su nicho climático Martínez (2009-2010).

\section{Materiales y métodos}

Inicialmente, se efectuó una revisión sistemática de información secundaria sobre la situación actual de las áreas protegidas de la zona andina ecuatoriana, en particular enfatizando en datos sobre su problemática general, superficie de las formaciones vegetales nativas, deforestación, tenencia de la tierra y acciones frente al cambio climático.

\subsection{Análisis de la distribución de las formaciones vegetales identificadas}

Se realizó en base a información existente sobre la distribución de las formaciones vegetales de la región andina (Sierra, 1999; Martínez, 2009-2010) en la que se caracterizaron 15 formaciones vegetales nativas partiendo desde la cota de los $1.600 \mathrm{msnm}$ hacia arriba: seis tipos de bosque, cinco de matorrales y cuatro de páramos. Se espacialiazaron los datos de cobertura natural de las áreas protegidas andinas, con lo que se obtuvieron dos mapas de las formaciones vegetales de la Zona Andina (uno correspondiente a 1999 y otro a 2010). Luego se realizó el modelamiento del comportamiento espacial de estas formaciones hacia 2020, utilizando las condiciones climáticas definidas por el modelo HadCM3 bajo el escenario A2, siguiendo el esquema de la dispersión máxima ajustada (Martínez, 2009-2010).

\subsection{Elaboración de Tablas comparati- vas de la superficie de las formacio- nes vegetales nativas}

Esta información se originó del análisis geográfico efectuado en los mapas respectivos, permitió realizar el análisis de las posibles incidencias del cambio climático (en especial del Efecto Invernadero) sobre territorios andinos, con especial énfasis en lo que sucede dentro de las áreas protegidas, considerando la distribución espacial de sus formaciones vegetales y su variación a lo largo del tiempo.

\section{Resultados y discusión}

En Ecuador, los Andes están compuestos en la parte norte por dos cordilleras, la occidental y la oriental, y prácticamente por una sola cordillera en la parte austral, sin contar claro con los vestigios de la cordillera amazónica; se extienden aproximadamente por $690 \mathrm{~km}$, con un ancho variable de este a oeste: de entre 120 a $200 \mathrm{~km}$ Baquero et al. (2004).

La zona andina ecuatoriana cubre una superficie aproximada de $106.600 \mathrm{~km}^{2}$. De Sur a Norte va entre los $05^{\circ} 02^{\prime}$ Sur y $01^{\circ} 11^{\prime}$ Norte y altitudinalmente entre las cotas de los $800 \mathrm{msnm}$ hasta los $6300 \mathrm{msnm}$ en la cima del Chimborazo (Martínez, 2009-2010).

Una gran diversidad climática caracteriza a esta región: la temperatura, correlacionada inversamente con 
la altitud, disminuye $0.6^{\circ} \mathrm{C}$ por cada $100 \mathrm{~m}$ de ascenso; sin embargo, la cercanía a los nevados y la influencia de corrientes de aire amazónicas y costeras modifican en parte los patrones térmicos generales de la región (Baquero et al., 2004).

\subsection{Las áreas protegidas de Ecuador}

El Sistema Nacional de Áreas Protegidas del Ecuador (SNAP) fue creado en 1976, a partir de la estrategia preliminar para la Conservación de las áreas Silvestres Sobresalientes del Ecuador, con el propósito de conservar la biodiversidad y el acervo histórico cultural, además de los vestigios, yacimientos y asentamientos arqueológicos del país (ECOLAP y MAE, 2007).

La superficie de las áreas protegidas terrestres equivale a aproximadamente el $19 \%$ del territorio nacional. El sistema abarca a las 24 provincias del país e incluye la mayor parte de ecosistemas con 40 formaciones vegetales -de las 46 existentes en Ecuador-, en cuatro regiones geográficas de Ecuador (http://ecuadortouristique.wordpress.com).

Además de albergar una biodiversidad única, las Áreas del SNAP son fuente de servicios ambientales claves, particularmente aquellos relacionados con las fuentes de agua dulce, la misma que es consumida en diferentes ciudades del país, utilizada en plantas hidroeléctricas y en agricultura (ECOLAP y MAE, 2007).

\subsection{Categorías de manejo de las áreas protegidas de Ecuador y síntesis de su problemática}

Dependiendo de sus características particulares, las áreas del SNAP poseen distintas categorías de manejo (Gobierno de la República del Ecuador, 1981): Parque Nacional, Reserva Ecológica, Reserva Biológica, Área Nacional de Recreación, Refugio de Vida Silvestre, Reserva de Producción Faunística.

Las áreas protegidas constituyen una parte notable de las estrategias de conservación del país. Sin embargo, por sí solas pudieran ser insuficientes para asegurar la conservación de diferentes especies nativas de flora y fauna. Algunos autores han estimado, que aún con los niveles de protección actuales, en las próximas décadas tal estrategia sólo podría conservar alrededor del $50 \%$ de las especies nativas de las zonas tropicales (Palmberg-Lerche, 1998).

En la Tabla 1, se reseña de manera general la problemática de las áreas protegidas del SNAP, no se considera en ella aún la incidencia del cambio climático como un problema real. Esta ausencia se entiende quizá porque el análisis se refiere al manejo de las mismas y no a un estudio de lo que las afecta en el campo de la conservación; sin embargo, en las acciones de manejo ya se debería considerar a este factor como una variable importante en la planificación de su administración.

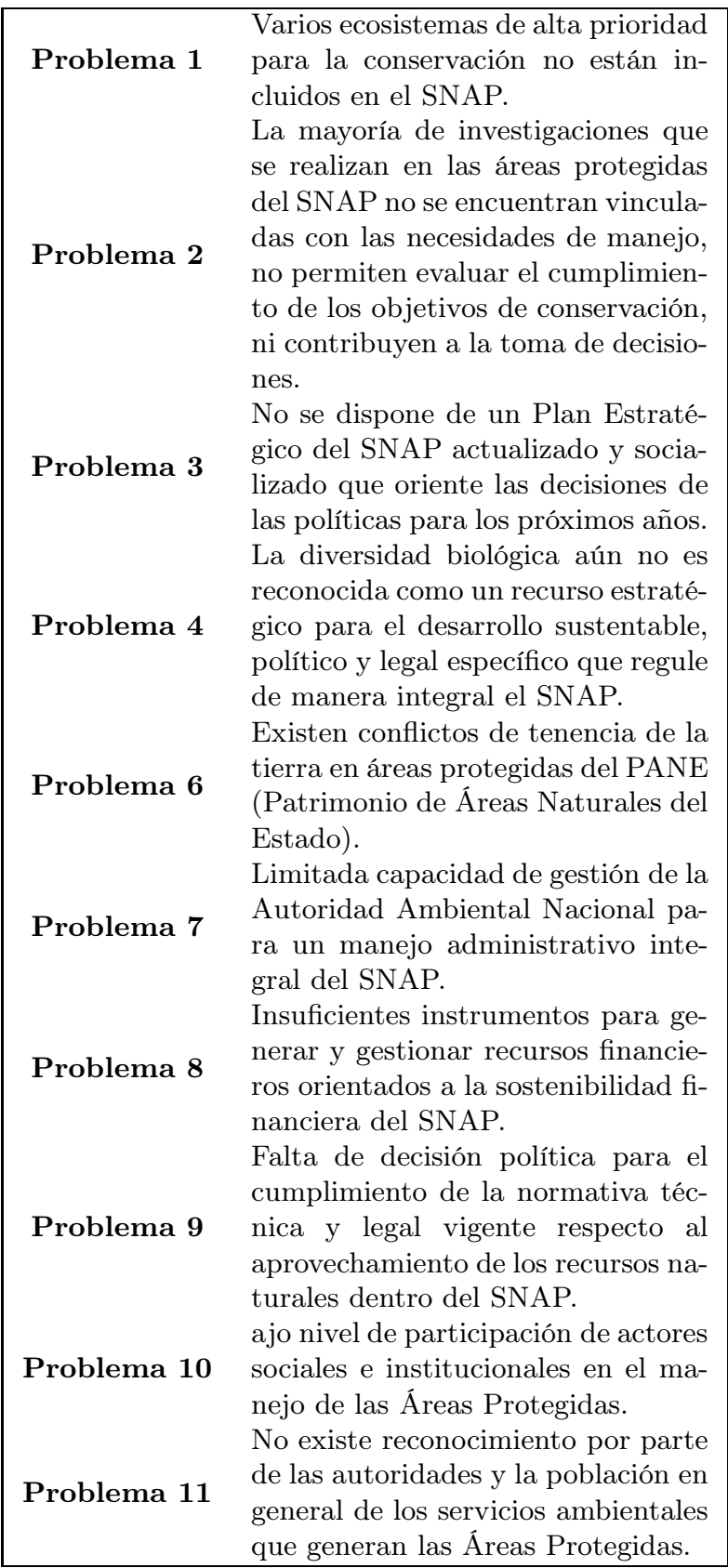

Tabla 1. Resumen de la problemática de manejo del SNAP. Fuente: Ministerio del Ambiente del Ecuador. 2007. Plan Estratégico del Sistema Nacional de Áreas Protegidas del Ecuador 2007-2016. 


\begin{tabular}{|c|c|c|}
\hline Área Protegida & $\begin{array}{l}\text { Superficie del Área } \\
\text { en } 2010 \text { (hectáreas) }\end{array}$ & Observaciones \\
\hline R.V.S. El Zarza & 3.643 & $\begin{array}{l}\text { Área andino-amazónica. De su superficie total, solo } 78 \\
\text { ha se encuentran por sobre los } 1.600 \mathrm{msnm} \text {. }\end{array}$ \\
\hline A.N.R. El Boliche & 392 & Área exclusivamente andina \\
\hline R.V.S. Pasochoa & 500 & Área exclusivamente andina \\
\hline R.G. Pululahua & 3.383 & Área exclusivamente andina \\
\hline R.E. Cofán Bermejo & 55.461 & $\begin{array}{l}\text { Área andino-amazónica. De su superficie total, solo } \\
5.267 \text { ha se encuentran por sobre los } 1.600 \mathrm{msnm} \text {. }\end{array}$ \\
\hline R.B. El Quimi & 9.071 & $\begin{array}{l}\text { Área andino-amazónica. De su superficie total, } 6.568 \\
\text { ha se encuentran por sobre los } 1.600 \mathrm{msnm} \text {. }\end{array}$ \\
\hline R.E. El Ángel & 15.715 & Área exclusivamente andina \\
\hline R.B. Cerro Plateado & 26.115 & $\begin{array}{l}\text { Área andino-amazónica. De su superficie total, } 19.441 \\
\text { ha se encuentran por sobre los } 1.600 \mathrm{msnm} \text {. }\end{array}$ \\
\hline P.N. Cajas & 28.544 & Área exclusivamente andina \\
\hline P.N. Cotopaxi & 32.255 & Área exclusivamente andina \\
\hline P.N. Yacuri & 43.091 & $\begin{array}{l}\text { Área casi exclusivamente andina; andino-amazónica. } \\
\text { De su superficie total, } 40.529 \text { ha se encuentran por } \\
\text { sobre los } 1.600 \mathrm{msnm} \text {. }\end{array}$ \\
\hline R.P.F. Chimborazo & 58.560 & Área exclusivamente andina \\
\hline R.E. Cotacachi Cayapas & 243.638 & $\begin{array}{l}\text { Área andino-costeña. De su superficie total, } 112.632 \text { ha } \\
\text { se encuentran por sobre los } 1.600 \mathrm{msnm} \text {. }\end{array}$ \\
\hline R.E. Antisana & 120.000 & $\begin{array}{l}\text { Area andino-amazónica. De su superficie total, } 116.298 \\
\text { ha se encuentran por sobre los } 1.600 \mathrm{msnm} \text {. }\end{array}$ \\
\hline R.E. Los Ilinizas & 149.900 & Área exclusivamente andina \\
\hline P.N. Podocarpus & 144.993 & $\begin{array}{l}\text { Área casi exclusivamente andina; andino-amazónica. } \\
\text { De su superficie total, } 134.782 \text { ha se encuentran por } \\
\text { sobre los } 1.600 \mathrm{msnm} \text {. }\end{array}$ \\
\hline P.N. Sumaco Napo-Galeras & 205.249 & $\begin{array}{l}\text { Area andino-amazónica. De su superficie total, } 143.080 \\
\text { ha se encuentran por sobre los } 1.600 \mathrm{msnm} \text {. }\end{array}$ \\
\hline P.N. Llanganates & 219.707 & Área exclusivamente andina \\
\hline P.N. Cayambe Coca & 403.103 & $\begin{array}{l}\text { Área andino-amazónica. De su superficie total, } 363.261 \\
\text { ha se encuentran por sobre los } 1.600 \mathrm{msnm} \text {. }\end{array}$ \\
\hline P.N. Sangay & 517.765 & $\begin{array}{l}\text { Area casi exclusivamente andina; andino-amazónica. } \\
\text { De su superficie total, } 439.706 \text { ha se encuentran por } \\
\text { sobre los } 1600 \mathrm{msnm} \text {. }\end{array}$ \\
\hline
\end{tabular}

Tabla 2. Superficie de las Áreas Protegidas de Ecuador localizadas total o parcialmente desde los $1.600 \mathrm{msnm}$ hacia arriba. 


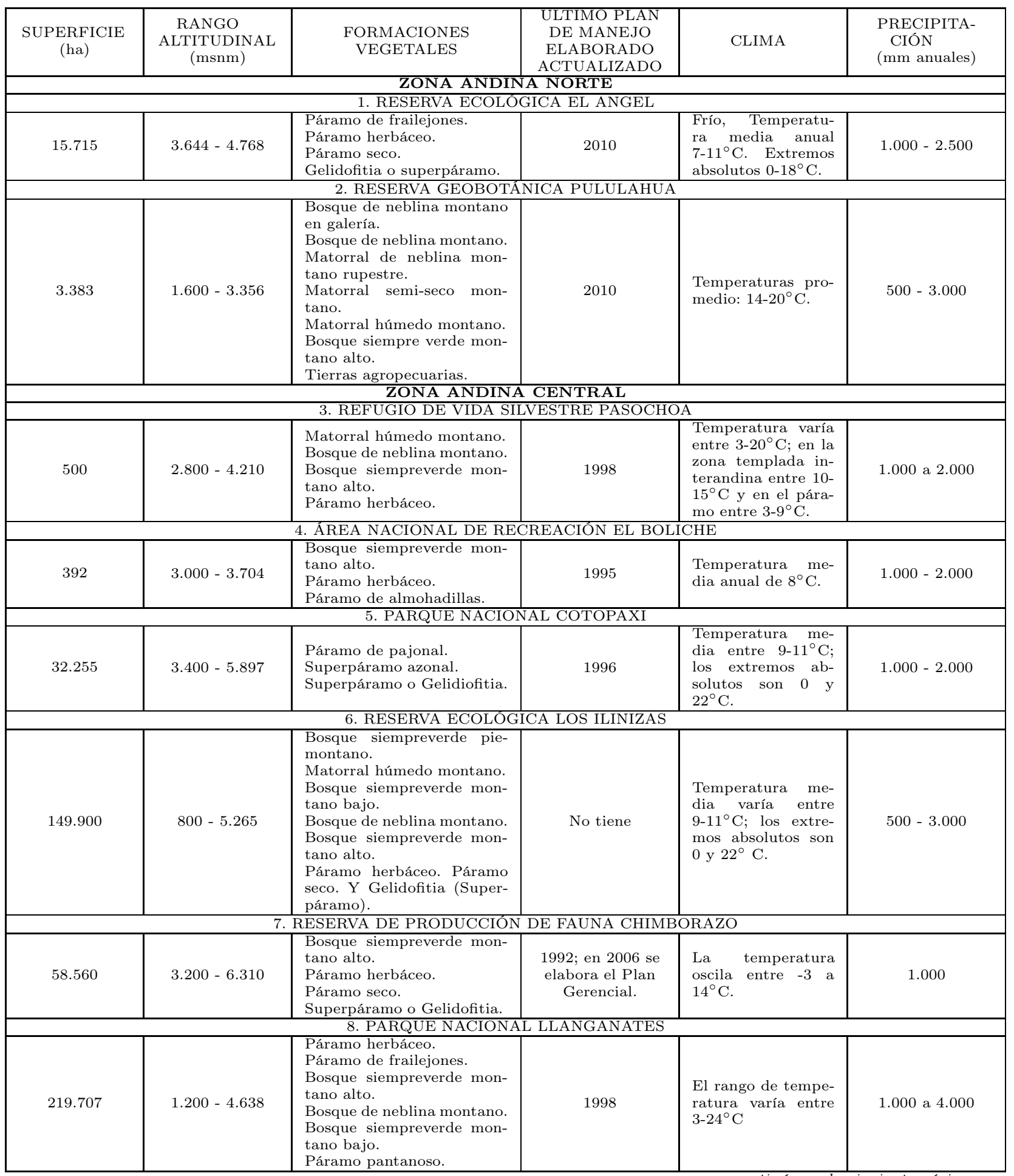




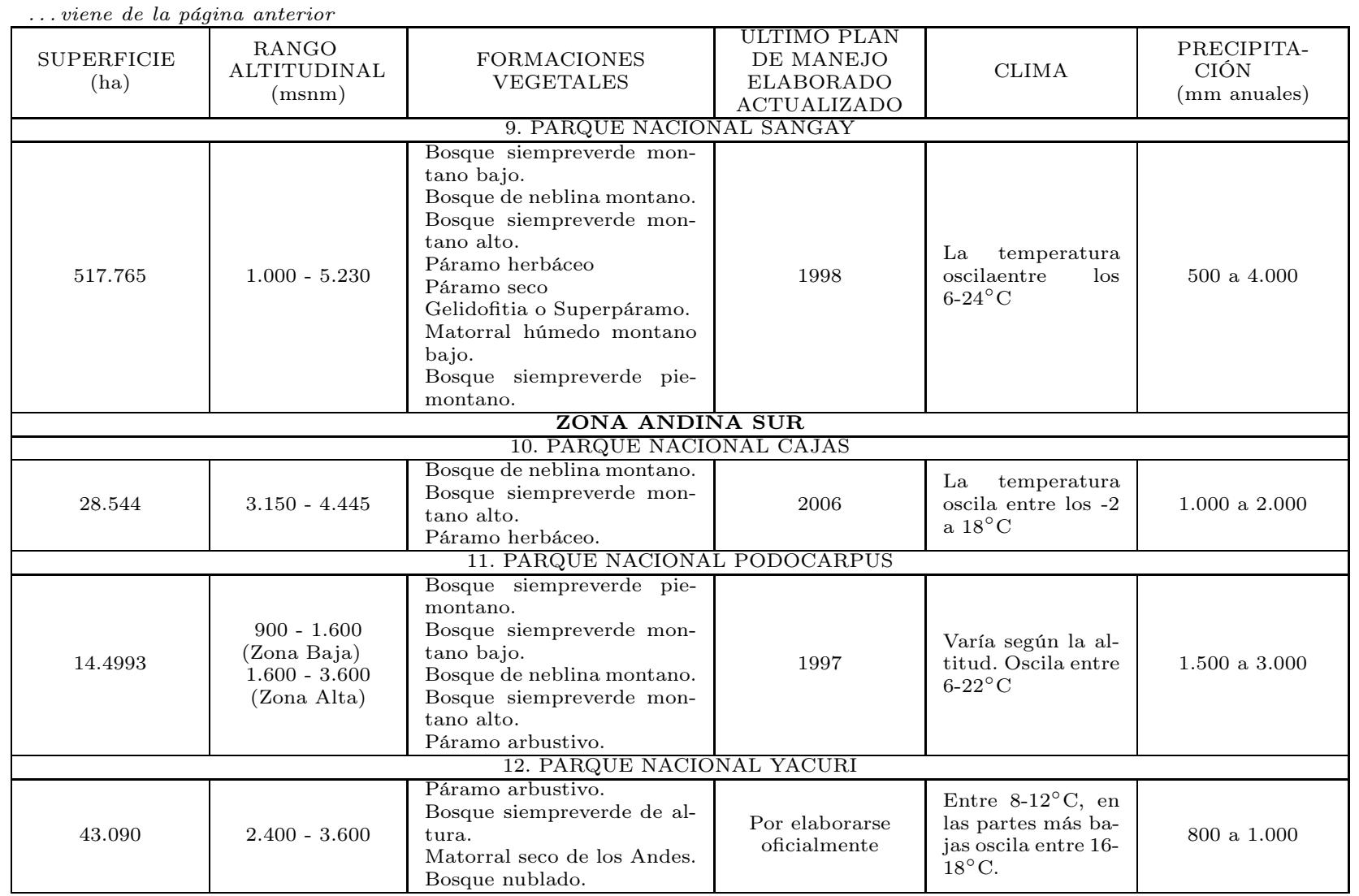

Tabla 3. Datos generales de las Áreas Protegidas Andinas de Ecuador. Elaboración personal en base a los Planes de Manejo de cada Área y a los trabajos de ECOLAP y MAE (2007) y de Sánchez y Benítez (2009).

\section{3 Áreas protegidas de Ecuador en la Zona Andina}

Doce son las áreas protegidas del SNAP exclusiva o casi exclusivamente andinas (Tabla 2), localizadas en tres regiones:

- Zona Andina Norte: Reserva Ecológica El Ángel, Reserva Geobotánica Pululahua.

- Zona Andina Central: Refugio de Vida Silvestre Pasochoa, Área Nacional de Recreación El Boliche, Parque Nacional Cotopaxi, Reserva Ecológica Los Ilinizas, Reserva de Producción de Fauna Chimborazo y los Parques Nacionales Llanganates y Sangay.

- Zona Andina Sur: Parques Nacionales Cajas, Podocarpus y Yacuri.

\subsection{Información general de las Áreas Protegidas Andinas}

En la Tabla 3 se presenta información relevante sobre estas áreas protegidas; a continuación algunos datos extras sobre procesos de deforestación y tenencia de la tierra.

\subsubsection{Reserva Ecológica El Ángel}

La deforestación es producida por la labranza de suelos de páramo para cultivos, además por quemas y tala de árboles nativos que se presentan esporádicamente.

No se han registrado invasiones, pero se debe recalcar que una buena parte de la reserva corresponde a propiedades privadas sustentadas con títulos auténti- 
cos. Esta situación ha generado conflictos de intereses, particularmente al momento de establecer restricciones para el uso del suelo (Rivadeneira-Roura y ColomaSantos, 2007b).

\subsubsection{Reserva Geobotánica Pululahua}

No se ha podido recopilar información referente a procesos de deforestación actuales; en cuanto a tenencia de la tierra, con la Revolución Liberal, estas tierras fueron confiscadas por el gobierno y entregadas a los huasipungueros locales. Los habitantes del cráter son recién llegados o descendientes de ex huasipungueros o patrones que continuaron explotando piedra caliza hasta 1941 (Rivadeneira-Roura y Coloma-Santos, 2007a).

\subsubsection{Refugio de Vida Silvestre Pasochoa}

Deforestación producida por labranza del páramo para cultivos, además por quemas y tala esporádicas. Rodeado por haciendas agrícolas y ganaderas; por convenio de cooperación (1997) corresponde su manejo a Fundación Natura. Por su cercanía a sitios poblados y agrícolas, está sometido a fuertes presiones externas, sobre todo en las partes bajas, adyacentes a las cuales existen actividades agrícolas y ganaderas que han modificado los bosques nativos, como por ejemplo introduciendo plantaciones de pinos (Coloma-Santos, 2007c).

\subsection{4 Área Nacional de Recreación El Boliche}

El área fue parte de la Hacienda Romerillos, en 1928 fue separada de esta hacienda y pasó a propiedad del Estado. La cobertura vegetal nativa ha sido reemplazada en muchos sectores por plantaciones de pino y ciprés, como consecuencia de la falta de un ordenamiento forestal nacional adecuado (Rivera, 2007d).

\subsubsection{Parque Nacional Cotopaxi}

Algunas hectáreas del parque han sido transformadas a bosques de pinos; en zonas adyacentes al parque hay fuerte presión por actividades agrícolas y ganaderas. A veces los finqueros queman el pajonal nativo, el problema de la quema es que ésta no es selectiva y con cierta frecuencia tiende a salirse del control de quienes la provocan. Existe un problema de mala distribución y acceso a la tierra en las áreas de amortiguamiento del parque, principalmente en algunas comunidades que aún tienen porciones de tierra comunal y otras que no las tienen (Coloma-Santos, 2007a).

\subsubsection{Reserva Ecológica Los Ilinizas}

Dentro de la reserva existen fuertes procesos de transformación de la vegetación natural a cultivos y pastos; la extracción de madera sostiene la economía de unas pocas familias de Chucchillán, La Esperanza y Pucayacu. También existe explotación esporádica de leña.

Algunos habitantes de comunidades cercanas afirman tener tierras con título de propiedad privada dentro de la reserva, por lo cual extraen su madera y la transforman en pastizales. En la reserva también existen concesiones mineras que cubren un $26 \%$ de vegetación natural, mientras que las áreas en trámite abarcan un $56 \%$ Coloma-Santos (2007d).

\subsubsection{Reserva de Producción de Fauna Chim- borazo}

La vegetación nativa se ve afectada por el pastoreo principalmente de ovejas y ganado vacuno; también una amenaza importante es la quema de pajonal que es un mecanismo a través del cual las comunidades de altura utilizan para tener pasto fresco y tierno para los animales. Por tanto, ganado y fuego son dos elementos que caracterizan a la presencia humana en estas zonas. El fuego destruye todo y después de un tiempo es poco probable que la biodiversidad del páramo se restituya.

En el área del Chimborazo existen muchas comunidades indígenas, interesantes por sus costumbres ancestrales que se han mantenido invariables desde tiempos remotos. Actualmente, las comunidades de campesinos que se ubican cerca de la reserva se dedican a la agricultura y al pastoreo extensivo e intensivo (Rivera, 2007e).

\subsubsection{Parque Nacional Llanganates}

Tiene algunas áreas con vegetación natural y otras con vegetación disturbada. La deforestación no es una actividad intensiva ni generalizada dentro del parque, no ha aumentado de magnitud porque los bosques nativos de la zona alta se ubican a gran distancia de las poblaciones, aunque en las zonas bajas existe extracción ilegal de madera.

En la actualidad, las poblaciones que habitan los páramos cercanos al parque son de indígenas y mestizos; tradicionalmente se dedicaban a la agricultura y 
más recientemente al pastoreo extensivo. En el sector del bosque nublado habitan colonos mestizos, de reciente asentamiento, provenientes de la sierra. Se dedican principalmente a la agricultura y hacen uso de los recursos naturales del parque por extracción de madera y cacería.

En muchos casos, las tierras de las comunidades están dentro de los límites del parque, gran parte de ellas legalizadas gracias a los procesos iniciados en la Reforma Agraria. Estas poblaciones tienen un mayor impacto en las provincias de Tungurahua y Cotopaxi y están concentradas en la parte sur y occidental del parque. La actividad humana dentro del área puede influir en un aumento en la extracción de los recursos naturales por parte de los pobladores en busca de satisfacer sus necesidades (Coloma-Santos, 2007b).

\subsubsection{Parque Nacional Sangay}

La zona alta del parque (pajonales) es la más afectada por incendios, provocando pérdidas tanto de diversidad como de cobertura vegetal; actualmente, este sector está ocupado por indígenas quichuas con origen Puruhá y Salasaca. Mientras que la zona baja del parque u oriental principalmente contiene en su zona de amortiguamiento comunidades Shuar y colonos provenientes de las provincias de Azuay y Cañar (Rivera, 2007c).

\subsubsection{Parque Nacional El Cajas}

Se han disminuído los incendios forestales y la extracción de plantas en épocas de Navidad. Al momento, no existen culturas nativas al interior del área; sin embargo, sí existen poblados y caseríos en los alrededores (Rivera, 2007a).

\subsubsection{Parque Nacional Podocarpus}

La disminución de tierras para la producción agropecuaria en la zona de amortiguamiento del parque, el incremento poblacional, la construcción de carreteras, entre otros factores, traen como consecuencia que los pobladores locales incursionen eventualmente en los territorios de esta área protegida y utilicen furtivamente sus recursos (Rivera, 2007b).

\subsubsection{Parque Nacional Yacuri}

No se ha determinado aún el porcentaje de deforestación actual en la zona, la declaratoria de parque na- cional es relativamente reciente; se han destinado algunos fondos iniciales para investigaciones que incluyen el desarrollo de su plan de manejo. Está área se encuentra alejada de zonas pobladas, por lo que se ha mantenido en buen estado de conservación, y de acuerdo al análisis de amenazas, ninguna comunidad o propietario tendría tierras dentro del parque nacional (Sánchez y Benítez, 2009).

\subsection{Capacidad de respuesta de las áreas protegidas frente al cambio climáti- co}

De conversaciones efectuadas con los encargados o técnicos de las áreas protegidas de la Sierra del Ecuador, se puede concluir que no existen en la mayoría de planes de manejo, temas referentes a cambio climático y/o efecto invernadero. En una de las áreas protegidas de la Sierra Norte (Pululahua), se menciona que se ha considerado al cambio climático para su nuevo plan de manejo. En la Reserva El Ángel se menciona que existe un plan de emergencias ante problemas climáticos pero es incipiente.

La capacitación sobre cambio climático no ha sido considerada en ninguna de las áreas protegidas, aunque el personal de algunas áreas ha participado de manera individual en talleres de difusión, mas no de capacitación; de igual manera en la mayoría de áreas no se cuenta con un plan de acción o mitigación frente a los efectos del cambio climático y tampoco con suficiente coordinación con la Subsecretaría de Cambio Climático del Ministerio del Ambiente, quizá por el hecho de que esta subsecretaría es relativamente nueva y su agenda todavía no contempla este tipo de interacciones con las áreas protegidas.

\subsection{Análisis de la distribución de las formaciones vegetales andinas}

Se recolectaron datos geográficos de vegetación a partir de los $1.600 \mathrm{msnm}$; el componente espacial de estos datos fue representado en un SIG, a través de un modelo vectorial, el cual proporciona una muy buena resolución espacial y debido a que este modelo efectúa una asignación de atributos asociada a una tabla de información para cada capa de datos espaciales; así, la información es representada por polígonos que definen límites y fronteras, lo cual establece un sistema de coordenadas en X y en Y. 
La estructura de datos utilizada en el modelo vectorial fue la estructura arco/nodo, representando una organización específica de los objetos y datos espaciales y su topología.

El modelo utilizado fue el georrelacional, el cual permite relacionar la base de datos de vegetación con la base de datos espaciales y permite efectuar un análisis espacial, proveyendo procedimientos que permiten integrar de manera coherente los criterios implicados.

La escala espacial para la representación adecuada de los datos tuvo dos componentes: el detalle, definido por el tamaño de la unidad mínima de mapeo y la extensión, o el tamaño del área de estudio. Esta relación hizo necesario trabajar los mapas temáticos en una escala de representación gráfica.

Para el desarrollo progresivo del análisis geográfico, se elaboraron tres mapas temáticos, los cuales contienen las siguientes capas a nivel cartográfico: Curvas de Nivel, Perfil del Ecuador, Áreas Protegidas, Coberturas de vegetación (1999, 2010, proyección a 2020).

\begin{tabular}{|l|r|}
\hline \multicolumn{1}{|c|}{$\begin{array}{c}\text { Formaciones Vegetales } \\
\text { Andinas }\end{array}$} & $\begin{array}{c}\text { Superficie para } \\
\text { 1999 hectáreas) }\end{array}$ \\
\hline $\begin{array}{l}\text { Bosque Siempreverde Montano } \\
\text { Amazónico }\end{array}$ & 101.922 \\
\hline $\begin{array}{l}\text { Bosque Siempreverde Montano Ba- } \\
\text { jo Andino }\end{array}$ & 754.256 \\
\hline $\begin{array}{l}\text { Bosque Tumbecino Deciduo Pre- } \\
\text { montano }\end{array}$ & 1.719 \\
\hline Bosque de Neblina Montano Alto & 870.818 \\
\hline $\begin{array}{l}\text { Bosque Siempre Verde Montano Al- } \\
\text { to }\end{array}$ & 241.024 \\
\hline $\begin{array}{l}\text { Bosque Siempre Verde Montano Ba- } \\
\text { jo Amazónico }\end{array}$ & 17.002 \\
\hline $\begin{array}{l}\text { Matorral Húmedo Montano Amazó- } \\
\text { nico }\end{array}$ & 201.076 \\
\hline $\begin{array}{l}\text { Matorral Húmedo Andino (Páramo } \\
\text { Arbustivo) }\end{array}$ & 166.071 \\
\hline Matorral Montano & 91.990 \\
\hline Matorral Seco Montano & 73.115 \\
\hline Matorral Seco Montano Andino & 53.063 \\
\hline Paramo Seco & $1^{\prime} 332.623$ \\
\hline Páramo Herbáceo & 50.025 \\
\hline Páramo de Frailejones & 227.892 \\
\hline Gelidofitia & 22.620 \\
\hline Nieves Perpetuas & 7.886 \\
\hline Cuerpos de Agua & 2764.813 \\
\hline Zona Intervenida & $\begin{array}{c}\text { Total de hectáreas de territorio an- } \\
\text { dino de Ecuador a partir de los 1.600 } \\
\text { msnm }\end{array}$ \\
\hline
\end{tabular}

Tabla 4. Formaciones vegetales en la zona andina de Ecuador para 1999.

\subsubsection{MAPA 1: Formaciones vegetales a partir de los 1.600 msnm (1999)}

Este mapa temático (Figura 1) fue realizado con el objeto de visualizar la vegetación existente hace 12 años en la zona andina del Ecuador, fue realizado en una escala gráfica de representación de 1:1'200.000.

Este mapa fue desarrollado en base al Mapa de Vegetación remanente del Ecuador (Sierra, 1999) en una escala real entre 1:1’000.000 y 1:250.000, se utilizó un modelo cartográfico que incluyó la identificación de las clases de vegetación del Ecuador continental y el uso del supuesto hídrico y la elevación para identificar patrones espaciales y la distribución teórica de las formaciones ecofisiológicas vegetales relevantes. Información sobre estas formaciones y sus superficies se muestran en la Tabla 4.

\subsubsection{MAPA 2: Formaciones Vegetales a partir de los $1.600 \mathrm{msnm}$ (2010)}

Para la elaboración de este mapa (Figura 2) se tomó como referencia la información cartográfica oficial de 2009, el objetivo fue el de contar con un mapa actual de las formaciones vegetales andinas, con el fin de visualizar el cambio que han tenido a lo largo de un período de 11 años a partir de 1999.

Este mapa fue realizado al igual que el anterior partiendo de los $1.600 \mathrm{msnm}$ hacia arriba, a una escala de representación de 1:1'200.000. Las formaciones vegetales con sus respectivas superficies se presentan en la Tabla 5 .

\subsubsection{MAPA 3: Formaciones Vegetales a partir de los $1.600 \mathrm{msnm}$ (2020)}

Para la elaboración de este mapa se usó un factor de tendencia de 10 años hacia el futuro, considerando las tasas de transformación del paisaje vigentes, cuya causa es la acción antrópica pero también factores relacionados con el cambio climático contemporáneo (calentamiento global), los cuales inciden en un cambio en la distribución futura de las formaciones vegetales montañosas (Yánez, 2009); así se calcularon las áreas de vegetación andina que se modificarían a partir de 2010 .

El mapa correspondiente (Figura 3) fue realizado al igual que los anteriores: a partir de los 1.600 msnm y a una escala de representación de 1:1'200.000; para ello se consideró principalmente el modelo de predicción de ocupación de ecosistemas en el futuro propuesto por Martínez (2009). Las formaciones vegetales con sus superficies para 2020 se presentan en la Tabla 6 . 


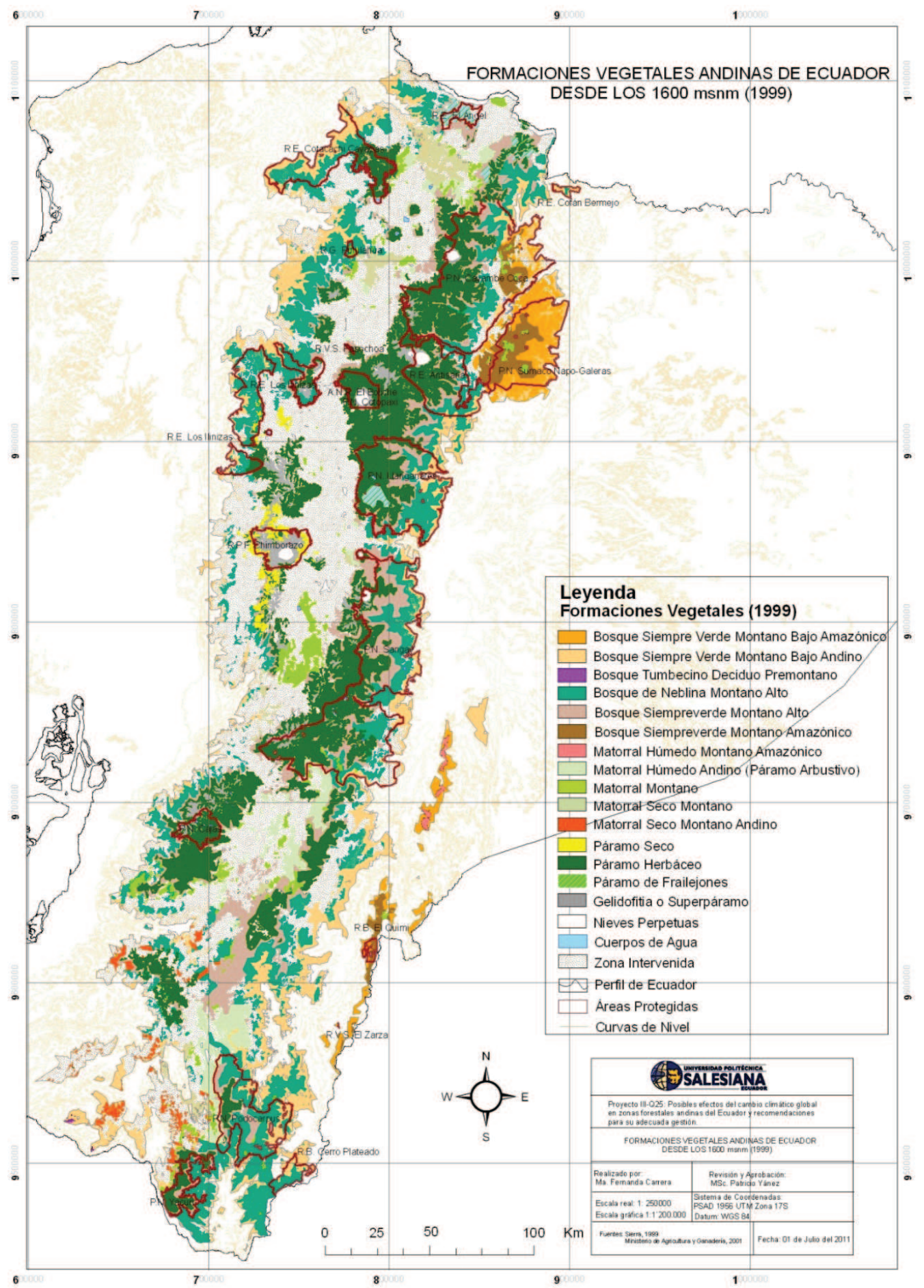

Figura 1. Formaciones vegetales andinas de Ecuador a partir de los 1.600 msnm (1999). 


\begin{tabular}{|l|r|}
\hline \multicolumn{1}{|c|}{$\begin{array}{c}\text { Formaciones Vegetales } \\
\text { Andinas }\end{array}$} & $\begin{array}{c}\text { Superficie para 2010 } \\
\text { (hectáreas) }\end{array}$ \\
\hline $\begin{array}{l}\text { Bosque Siempreverde Mon- } \\
\text { tano Amazónico }\end{array}$ & 93.580 \\
\hline $\begin{array}{l}\text { Bosque Siempreverde Mon- } \\
\text { tano Bajo Andino }\end{array}$ & 597.227 \\
\hline $\begin{array}{l}\text { Bosque Tumbecino Deciduo } \\
\text { Premontano }\end{array}$ & 1.719 \\
\hline $\begin{array}{l}\text { Bosque de Neblina Montano } \\
\text { alto }\end{array}$ & 742.663 \\
\hline $\begin{array}{l}\text { Bosque Siempre Verde Mon- } \\
\text { tano Alto }\end{array}$ & 631.201 \\
\hline $\begin{array}{l}\text { Bosque Siempre Verde Mon- } \\
\text { tano Bajo Amazónico }\end{array}$ & 241.024 \\
\hline $\begin{array}{l}\text { Matorral Húmedo Montano } \\
\text { Amazónico }\end{array}$ & 16.150 \\
\hline $\begin{array}{l}\text { Matorral Húmedo An- } \\
\text { dino(Páramo Arbustivo) }\end{array}$ & 201.076 \\
\hline Matorral Montano & 173.887 \\
\hline Matorral Seco Montano & 65.694 \\
\hline $\begin{array}{l}\text { Matorral Seco Montano An- } \\
\text { dino }\end{array}$ & 73.115 \\
\hline Paramo Seco & 53.063 \\
\hline Páramo Herbáceo & 1324.636 \\
\hline Páramo de Frailejones & 50.025 \\
\hline Gelidofitia & 227.892 \\
\hline Nieves Perpetuas & 22.620 \\
\hline Cuerpos de Agua & 7.886 \\
\hline Zona Intervenida & 312.241 \\
\hline $\begin{array}{l}\text { Total de hectáreas de territo- } \\
\text { rio andino de Ecuador a par- } \\
\text { tir de los 1.600 msnm }\end{array}$ & $\begin{array}{r}1300 \\
\hline\end{array}$ \\
\hline
\end{tabular}

Tabla 5. Formaciones vegetales en la zona andina de Ecuador para 2010.

\subsection{Consideraciones sobre la distribu- ción de las formaciones vegetales andinas dentro de las áreas prote- gidas}

Para este análisis se tomaron en cuenta 12 formaciones vegetales eminentemente andinas (Tabla 7) (Martínez, 2009-2010) y a la vez 11 de las 12 Áreas Protegidas predominantemente andinas (Tabla 8).

En la presente sección se consideran solo los datos de los mapas generados para 2010 y para 2020 (Figuras 2 y 3$)$.

\begin{tabular}{|c|c|}
\hline $\begin{array}{c}\text { Formaciones Vegetales } \\
\text { Andinas }\end{array}$ & $\begin{array}{c}\text { Superficie para } 2020 \\
\text { (hectáreas) }\end{array}$ \\
\hline $\begin{array}{l}\text { Bosque Siempreverde Mon- } \\
\text { tano Amazónico }\end{array}$ & 85.921 \\
\hline $\begin{array}{l}\text { Bosque Siempreverde Mon- } \\
\text { tano Bajo Andino }\end{array}$ & 472.891 \\
\hline $\begin{array}{l}\text { Bosque Tumbecino Deciduo } \\
\text { Premontano }\end{array}$ & 1.719 \\
\hline $\begin{array}{l}\text { Bosque de Neblina Montano } \\
\text { alto }\end{array}$ & 486.383 \\
\hline $\begin{array}{l}\text { Bosque Siempre Verde Mon- } \\
\text { tano Alto }\end{array}$ & 457.517 \\
\hline $\begin{array}{l}\text { Bosque Siempre Verde Mon- } \\
\text { tano Bajo Amazónico }\end{array}$ & 241.024 \\
\hline $\begin{array}{l}\text { Matorral Húmedo Montano } \\
\text { Amazónico }\end{array}$ & 15.342 \\
\hline $\begin{array}{l}\text { Matorral Húmedo Andino } \\
\text { (Páramo Arbustivo) }\end{array}$ & 201.076 \\
\hline Matorral Montano & 172.071 \\
\hline Matorral Seco Montano & 46.914 \\
\hline $\begin{array}{l}\text { Matorral Seco Montano An- } \\
\text { dino }\end{array}$ & 73.115 \\
\hline Paramo Seco & 53.062 \\
\hline Páramo Herbáceo & 951.111 \\
\hline Páramo de Frailejones & 50.025 \\
\hline Gelidofitia & 227.892 \\
\hline Nieves Perpetuas & 20.620 \\
\hline Cuerpos de Agua & 7.886 \\
\hline Zona Intervenida & $4^{\circ} 571.131$ \\
\hline $\begin{array}{l}\text { Total de hectáreas de territo- } \\
\text { rio andino de Ecuador a par- } \\
\text { tir de los } 1.600 \mathrm{msnm}\end{array}$ & $8^{‘} 135.700$ \\
\hline
\end{tabular}

Tabla 6. Formaciones vegetales en la zona andina de Ecuador y sus superficies para 2020

Para efectuar el modelamiento hacia 2020, se consideraron condiciones climáticas definidas por el modelo HadCM3 atmósfera-océano, creado en el Hadley Center de Inglaterra en 2000, por Gordon y Pope. Para la resolución atmosférica el modelo dispone de 19 niveles (una malla de $96 \times 73$ celdas) y para el océano 20, también cuenta con un total de 14 bandas espectrales y dispone de un nuevo esquema para el tratamiento del agua sobre la superficie terrestre (nieve y hielo). Podríamos decir que se trata de un modelo relativamente reciente y con características aceptables (〈http://elclima.esparatodos.es/hadcm3/index.htm $\rangle$ ). 


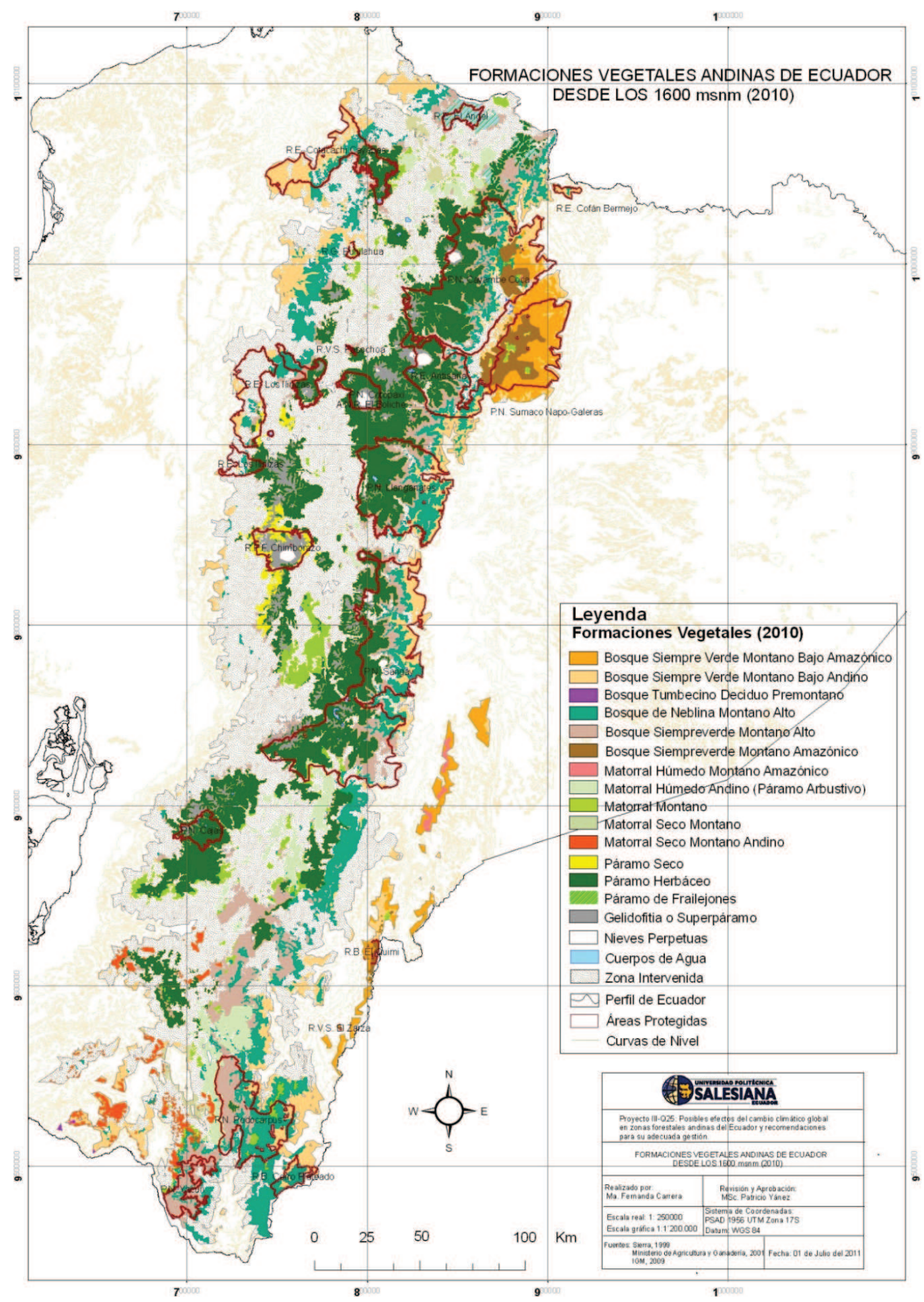

Figura 2. Formaciones vegetales andinas de Ecuador a partir de los $1.600 \mathrm{msnm}$ (2010). 


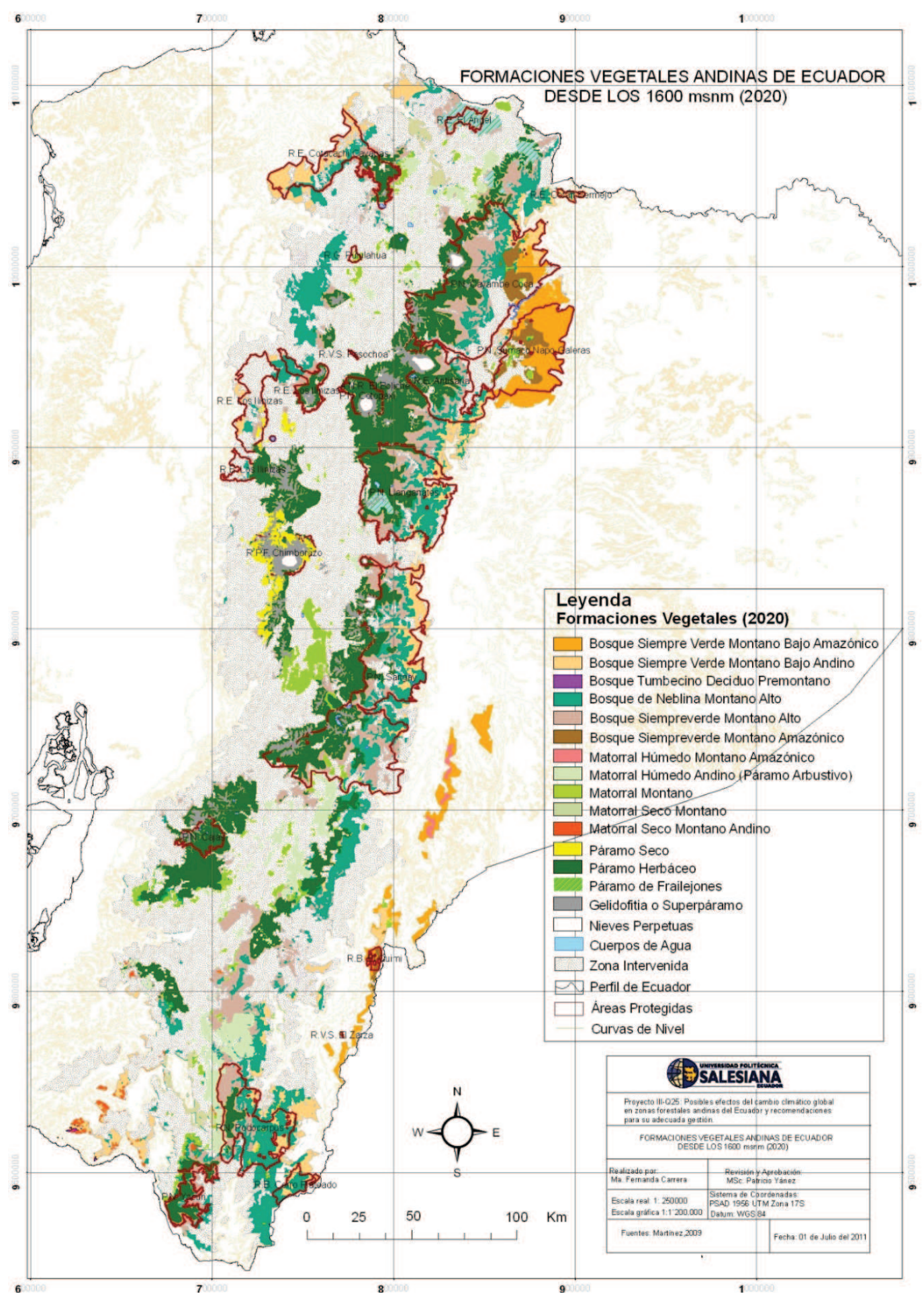

Figura 3. Formaciones vegetales andinas de Ecuador a partir de los $1.600 \mathrm{msnm}$ (2020). 


\begin{tabular}{|c|c|c|}
\hline $\mathbf{N}^{\circ}$ & $\begin{array}{l}\text { Formaciones } \\
\text { vegetales }\end{array}$ & $\begin{array}{c}\text { Correspondencia } \\
\text { con las áreas } \\
\text { protegidas de la } \\
\text { zona andina } \\
\end{array}$ \\
\hline 1 & $\begin{array}{l}\text { Bosque semideciduo } \\
\text { montano bajo - Bsdmb }\end{array}$ & $\begin{array}{r}\text { No se encuentra } \\
\text { representado en } \\
\text { ninguna área. }\end{array}$ \\
\hline 2 & $\begin{array}{l}\text { Bosque siempreverde } \\
\text { piemontano - Bsvp }\end{array}$ & $\begin{array}{r}\text { Ilinizas, Llanganates, } \\
\text { Sangay. }\end{array}$ \\
\hline 3 & $\begin{array}{l}\text { Bosque siempreverde } \\
\text { montano bajo - Bsvmb }\end{array}$ & $\begin{array}{l}\text { Podocarpus, Sangay, } \\
\text { Llanganates, ILinizas }\end{array}$ \\
\hline 4 & $\begin{array}{l}\text { Bosque de neblina mon- } \\
\text { tano bnm }\end{array}$ & $\begin{array}{r}\text { Podocarpus, ILinizas, } \\
\text { Sangay, Llanganates, } \\
\text { Pululahua }\end{array}$ \\
\hline 5 & $\begin{array}{l}\text { Bosque siempreverde } \\
\text { montano alto - Bsvma }\end{array}$ & $\begin{array}{r}\text { Pululahua, Pasochoa, } \\
\text { Ilinizas, LLanganates, } \\
\text { Cajas, Podocarpus, } \\
\text { Cotopaxi, Sangay , El } \\
\text { Ángel. }\end{array}$ \\
\hline 6 & Matorral húmedo - Mh & $\begin{array}{r}\text { Pululahua, Sangay, } \\
\text { Podocarpus. }\end{array}$ \\
\hline 7 & Matorral seco - Ms & Sangay, Pululahua. \\
\hline 8 & Páramo arbustivo - $\mathrm{Pa}$ & $\begin{array}{r}\text { Podocarpus, } \\
\text { Pululahua, Sangay. }\end{array}$ \\
\hline 9 & Páramo seco - Ps & Chimborazo. \\
\hline 10 & $\begin{array}{l}\text { Páramo de frailejones - } \\
\text { Pf }\end{array}$ & El Ángel, Llanganates. \\
\hline 11 & Páramo herbáceo - Ph & $\begin{array}{r}\text { Pasochoa, Cotopaxi, } \\
\text { Podocarpus, Boliche, } \\
\text { Ilinizas, Chimborazo, } \\
\text { Llanganates, Sangay, } \\
\text { Cajas }\end{array}$ \\
\hline 12 & Superpáramo - Sp & $\begin{array}{r}\text { Cotopaxi, Sangay, } \\
\text { Chimborazo }\end{array}$ \\
\hline
\end{tabular}

Tabla 7. Formaciones vegetales nativas andinas y pertenencia a las áreas protegidas del presente. Elaboración de los autores en base a planes de manejo de las áreas protegidas.

Se debe recordar que este tipo de modelos desarrollan representaciones matemáticas del sistema climático, expresadas en software especializado. Los productos resultantes son modelos sobre el futuro del clima promedio, basados en hipótesis sobre las variables que los condicionan. La factibilidad de estos modelos depen- de de que tan acertadas hayan sido las hipótesis y que tan adecuadas las herramientas científicas y de cálculo usadas.

Los modelos o escenarios climáticos son fundamentales para entender las causas y efectos probables del calentamiento global, así como para tomar medidas adecuadas para minimizar sus efectos. Estos modelos han mejorado sustancialmente a lo largo de los años, al perfeccionarse la ciencia en la que se basan, al extenderse y mejorarse las bases de datos sobre las que se apoyan y al ampliarse las herramientas de cálculo que emplean. Todo ello va permitiendo incorporar un mayor número de componentes climáticos e ir refinando la malla espacial sobre la que se realizan los cálculos.

La mayoría de modelos generan escenarios climáticos que representan los efectos de la variación del clima futuro basados en suposiciones sobre emisiones de gases de efecto invernadero y otros contaminantes y el efecto que tendría el aumento de las concentraciones de estos gases sobre el clima global. Por tanto, describen cómo se modificará el clima del planeta como consecuencia de una alteración de la composición atmosférica generada por las actividades humanas.

En la actualidad, la mayoría de escenarios climáticos se encuentran basados en el Informe Especial del IPCC (Grupo Intergubernamental de Expertos sobre el Cambio Climático, 2000) sobre escenarios de emisiones. En él se elaboraron cuatro líneas evolutivas (A1, A2, B1 y B2), en las que se describen las fuerzas determinantes en las emisiones de gases de efecto invernadero y aerosoles, así como su evolución durante el siglo XXI tanto en términos globales como regionales. Cada línea evolutiva representa un nivel de desarrollo divergente en cuestiones demográficas, sociales, económicas y tecnológicas.

En términos simples, las cuatro líneas evolutivas combinan dos series de tendencias divergentes: una serie desarrolla las variaciones entre valores económicos y ambientales; la otra serie explora las variaciones entre mayor globalización y regionalización.

Se puede decir que los escenarios consideran diferentes condiciones del desarrollo global para las próximas décadas y son, en un sentido amplio, escenarios del estado y crecimiento de la población y la economía. Las dos grandes familias de escenarios conllevan a estimar las emisiones globales de gases de efecto invernadero (Magaña et al., 2011). 


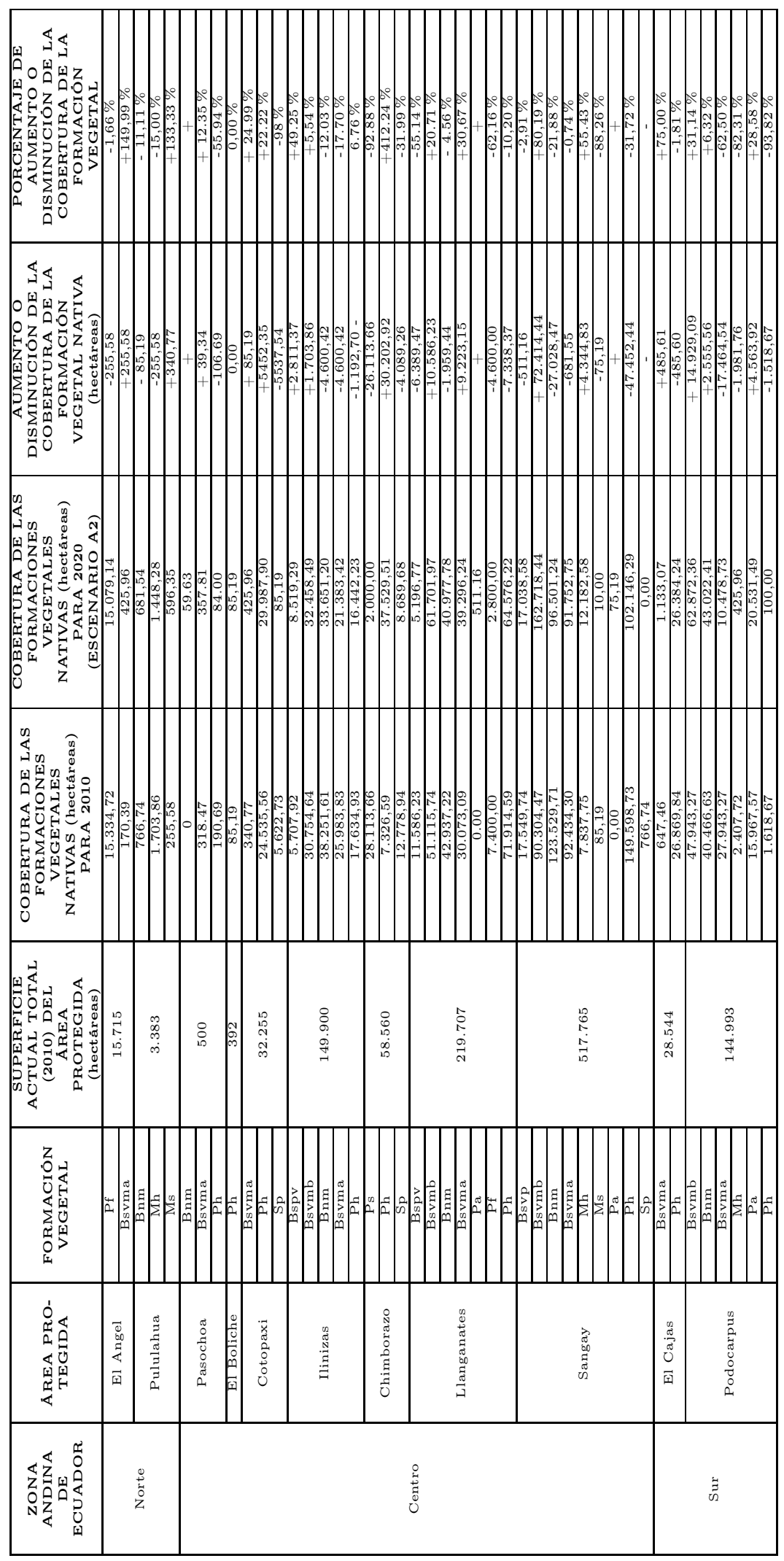

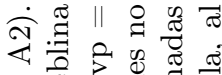

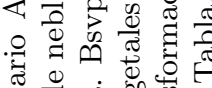

สี

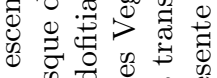

४ 0.0

$\circ$ ○

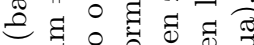

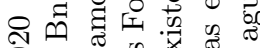

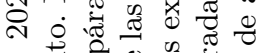

व

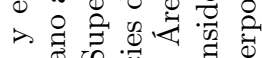

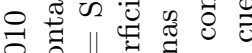

จ

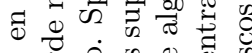

ᄒै

ఫิ

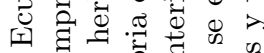

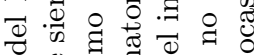

๘

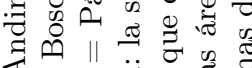

य $\|$ 崖完

ॠ

요요 $\dot{8} \overline{0}$

๘ी

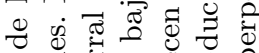

马 0 :

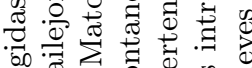

की

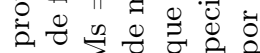

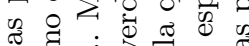

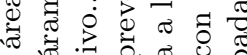

पै

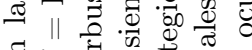

वै 4 के

के

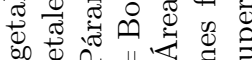

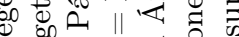

$>$ \& 0 웜

के के है

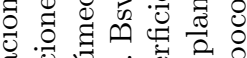

范

๑

约

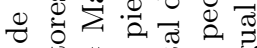

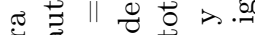

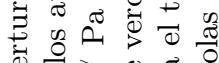

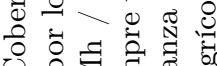

\%之 द्वे

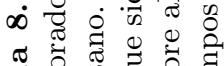

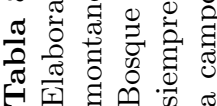


El escenario A2 del IPCC, asume un crecimiento continuo de la población mundial; sus características más distintivas son la autosuficiencia y la conservación de las identidades locales, con un desarrollo económico orientado básicamente a las regiones y al crecimiento económico por habitante, así como el cambio tecnológico, más fragmentado y más lento que en otros escenarios (IPCC, 2000).

La dispersión máxima ajustada asume la ocupación de una formación vegetal o paisaje particular en los sitios en donde su idoneidad climática ajustada sea mayor a la de las demás formaciones.

\subsubsection{Variación de la superficie de las forma- ciones vegetales de las áreas protegidas de 2010 a 2020}

En la Figura 2 se puede apreciar el mapa con la disposición de las áreas protegidas de la Zona Andina en el presente (2010) y las formaciones vegetales de cada una, al contrastar esta información con la Figura 3 (Mapa al año 2020), uno de los detalles más claros que se observa, es que las áreas de Páramo seco, Páramo herbáceo y Páramo de frailejones en las reservas que los tienen por lo general se reducen, dando paso al páramo arbustivo y a formaciones boscosas típicas de menores altitudes (Tabla 8), por lo que se deduce que los ecosistemas considerados más ricos como los páramos de frailejones y los bosquetes parameros de altura (conformados por Polylepis principalmente) son los más vulnerables a los cambios climáticos.

En la Reserva Ecológica El Ángel se registran cambios en la formación de páramo, habiendo una pequeña disminución hacia 2020; en cambio, el Bosque siempreverde montano alto aumenta en superficie.

En la Reserva Geobotánica Pululahua disminuyen el bosque de neblina montano y el matorral húmedo dando paso a un avance en superficie del matorral seco.

En el Refugio de Vida Silvestre Pasochoa, el bosque siempre verde montano aumenta, pero disminuye el páramo herbáceo.

En el Área Nacional de Recreación El Boliche el páramo herbáceo se mantiene igual.

En el Parque Nacional Cotopaxi, el bosque siempre montano alto y el páramo herbáceo aumentan pero disminuye notablemente el Superpáramo.

En la Reserva Ecológica Los Ilinizas aumentan el bosque siempre verde piemontano y el bosque siempre verde montano bajo y disminuyen los bosques de ne- blina montano y el páramo herbáceo.

En la Reserva de Producción de Fauna Chimborazo aumenta el páramo herbáceo y disminuye el superpáramo y el páramo seco.

En el Parque Nacional Llanganates disminuyen en superficie el páramo herbáceo, el bosque siempreverde piemontano, el bosque de neblina montano, mientras que aumentan el bosque siempreverde montano alto y el bosque siempreverde montano bajo.

En el Parque Nacional Sangay disminuyen de manera importante el páramo herbáceo y el superpáramo; disminuyen ligeramente el bosque siempreverde piemontano y el bosque siempre verde montano alto; mientras que aumentan de manera importante el bosque siempre verde montano bajo, los matorrales húmedos y el páramo arbustivo.

En el Parque Nacional El Cajas aumenta el bosque siempre verde montano bajo y disminuye el páramo herbáceo.

El páramo arbustivo aumenta en el Parque Nacional Podocarpus, al igual que el bosque siempre verde montano bajo, el Bosque de neblina montano. Disminuyendo notoriamente el bosque siempreverde montano alto y los matorrales húmedos.

A manera de resumen se puede decir que las formaciones de Páramo herbáceo y de frailejones así como el superpáramo en la mayoría de las áreas protegidas de la zona andina disminuyen su cobertura, trayendo como consecuencia una afectación negativa a los niveles de almacenamiento y liberación gradual actuales del agua (propia de estos ecosistemas).

Del análisis multitemporal realizado se concluye que el Parque Nacional Llanganates es el área que mayor cantidad de formaciones vegetales de altura (Páramos herbáceos y de frailejones) va a perder (favoreciendo el avance de formaciones de zonas más bajas, como bosques), seguido de la Reserva de Producción Faunística Chimborazo (páramo seco y superpáramo), el Parque Nacional Sangay y la Reserva de Vida Silvestre Pasochoa (Tabla 8).

\subsubsection{Consideraciones finales}

En estudios similares se ha mostrado que el impacto del cambio climático causaría una tendencia a la desertificación, especialmente en tres áreas críticas: una de ellas la Región interandina, especialmente en las provincias centrales (Cáceres, 2001). Estas conclusiones coinciden con los datos del presente estudio para el año 2020, en 
el que se destaca la disminución de bosques y bosquetes de altura y de páramos herbáceo, páramo de frailejones y superpáramo.

Cabe destacar que la aplicación de modelos de idoneidad se usa como una herramienta para investigar potenciales cambios tanto a nivel de especies como de formaciones vegetales; la aplicación de esta metodología, considerando las áreas protegidas como elemento de interés es una variación técnica con mucho potencial, tanto para analizar los usos presentes y futuros de los territorios de estas áreas, como para ayudar en la elaboración de estrategias de minimización de impactos del cambio climático y de su componente principal: el calentamiento global.

También el perfeccionamiento de estos modelos permitirá un uso cada vez más amplio por parte de diferentes investigadores y planificadores ambientales.

Sin embargo, se debe destacar que ningún modelo científico es perfecto y casi siempre es posible, con el tiempo, optimizarlo.

El desplazamiento espacial (altitudinal en el presente caso) de las formaciones vegetales no es un evento nuevo, se sabe de eventos en los que tal desplazamiento puede provocar la disminución en la superficie de tales formaciones, su aumento o su transformación (Yánez, 2009).

Por otra parte, se conoce que para Ecuador las variaciones contemporáneas de la temperatura tienden al alza (ya el Instituto Nacional de Meteorología e Hidrología de Ecuador -INAMHI- ha iniciado varios estudios en este sentido, enunciando que en 14 estaciones meteorológicas investigadas, se observa una tendencia al incremento de la temperatura media anual, con mayor intensidad en la región interandina); asimismo, enuncian que las temperaturas mínimas y máximas absolutas también tienden a ser cada vez más altas, mientras que la variación de la precipitación es bastante irregular (Cáceres et al., 1998).

A nivel latinoamericano, en los Andes neotropicales, según Cuesta y Chiriboga (2010), Salas (2009) y otros investigadores, se señala que las áreas prioritarias de conservación están sufriendo disminuciones en sus niveles de biodiversidad a causa del cambio climático, ocasionando a la vez la reducción de ecosistemas sensibles debido a la fragmentación del hábitat, la desertificación de ambientes naturales montañosos tropicales (ej.: bosques de neblina, pie de monte, bosques alto andinos y páramos), patrones de precipitación irregulares, principalmente; este escenario desafortunadamente también parece estar ocurriendo en Ecuador y de acuerdo a diferentes diagnósticos realizados a nivel regional, como el presente, se demuestra que el problema está afectando ya a varios países a lo largo de la Cordillera de los Andes, desde el occidente de Venezuela hasta el norte de Chile y oeste de Bolivia.

Por otro lado, para Delgado (2008), en la región interandina alta incluso es previsible que en las décadas futuras lleguen a converger especies de plantas de ambas vertientes de los Andes, creándose posiblemente nuevas combinaciones de especies y por consiguiente, nuevos ecosistemas.

El mismo autor señala que cualquier cambio en el clima regional podría amenazar la permanencia de varias áreas protegidas. En Ecuador, este efecto pudiera ya estar ocurriendo, como en el caso de la Reserva Pululahua, que a decir de los guardaparques está perdiendo humedad al desaparecer gradualmente la neblina constante que la caracterizaba, lo cual hace que los niveles de agua en los ríos y riachuelos locales se reduzcan lentamente, al punto de que en ciertos meses se tiene que planificar ya la compra de agua para atender a los visitantes de la reserva.

También es importante mencionar los efectos locales y regionales que pueden causar las variaciones climáticas en torno a la pérdida y/o desplazamiento espacial de algunas formaciones vegetales y la vulnerabilidad de los ecosistemas, especialmente los de alta montaña; en este sentido, Yánez (2009) señala que cada especie vegetal se desarrolla en ámbitos geográficos determinados (latitudinal y altitudinalmente) y tiende a reubicarlos cuando algún cambio climático la afecta; por esta razón, formaciones vegetales andinas como el bosque nublado, el páramo y el superpáramo constituyen elementos paisajísticos móviles en el espaciotiempo y han variado su ubicación y extensión durante cambios climáticos globales de origen natural y eventualmente pudieran hacerlo también como respuesta a cambios climáticos de origen antrópico.

Otros autores también llaman la atención sobre la afectación que pudieran estar sufriendo en los últimos años formaciones vegetales andinas tales como: matorral húmedo montano, matorral seco, páramo seco, páramo herbáceo y superpáramo (Baquero et al., 2004), los cuales han perdido porcentajes importantes de su cobertura.

También estudios como los de Delgado (2008) y Martínez (2009-2010) coinciden con los resultados de la presente investigación, al referir que son los páramos 
y bosques montanos de altitudes superiores los que se encuentran sometidos a una importante intervención directa e indirecta por parte del ser humano.

Los ecosistemas con mayores probabilidades de mantenerse por más tiempo invariablemente serán aquellos que muestren un mayor tamaño y mayor continuidad actuales (no los de superficies pequeñas o fragmentadas): este mayor tamaño y continuidad disminuiría ostensiblemente las probabilidades de su transformación o desaparición futuras, las cuales se generan principalmente desde los bordes del ecosistema. Por tanto, en algunas áreas protegidas, inclusive podría resultar necesario que se manejen criterios de conectividad mediante el establecimiento de corredores ecológicos que permitan mantener la biodiversidad local y aumentar la superficie protegida.

Algunas formaciones vegetales o ecosistemas considerados más estables (entre otros algunos ubicados en flancos de cordillera) podrían albergar con mayor éxito a poblaciones de flora y fauna nativas en el futuro y a la vez podrían ser considerados como de interés para la conservación y para el diseño e implementación efectiva de estos corredores ecológicos.

\section{Conclusiones y recomendacio- nes}

En Ecuador, se han realizado esfuerzos por mantener las áreas protegidas mediante el establecimiento de normas y políticas, realización de trabajos comunitarios, declaratorias de nuevas áreas, etc.; sin embargo, los impactos ambientales y sociales de diversa índole sumados a los últimos efectos observados relacionados con el cambio climático, tienden a debilitar la gestión de tales áreas. Por tanto, resulta imperativo que se fomente la generación del conocimiento real de toda esta problemática de manera cooperativa, se difundan muy ampliamente los resultados de tales investigaciones y se generen actividades emergentes de optimización del manejo de nuestras áreas protegidas.

En los Andes Tropicales (zona en la que coinciden altos índices de biodiversidad y riqueza de especies con una alta densidad poblacional humana), además de encontrarse algunas de las áreas más importantes para la conservación de la biodiversidad del planeta, existen serios conflictos entre la conservación de las especies nativas y las actividades de desarrollo humano.

Dentro de este contexto, los efectos del cambio cli- mático sobre las formaciones vegetales nativas pudieran influir en la distribución de estas formaciones como en la composición de las mismas; por tanto, resulta necesario que se adopten medidas tendientes a proteger mucho más las actuales áreas protegidas, así como sus límites y comunidades características.

El diagnóstico efectuado sobre la situación actual de las áreas protegidas andinas de Ecuador -la mayoría de las cuales no cuentan con medidas de contingencia para enfrentar el cambio climático y el calentamiento global- llama a la profunda reflexión de la sociedad ecuatoriana en general. Dentro de este escenario, se amerita urgentemente la integración de medidas de contingencia técnicamente bien diseñadas, integradas en los respectivos planes de manejo. Igualmente, urge alcanzar un nivel de integración técnica y cooperativa mucho mayor entre las diferentes instancias gubernamentales y no gubernamentales que corresponda para iniciar un trabajo conjunto relativamente urgente que salvaguarde la integridad del Sistema Nacional de Âreas Protegidas del país.

\section{Agradecimientos}

A la Universidad Politécnica Salesiana, por su apoyo a través del fondo de investigación del Proyecto III-Q25: "Posibles efectos del Cambio Climático Global en zonas forestales andinas del Ecuador y recomendaciones para su adecuada gestión".

A guardaparques y autoridades de las diferentes áreas protegidas incluidas dentro del presente estudio, quienes nos atendieron a veces en campo, a veces vía telefónica, brindándonos cordialmente información general sobre sus respectivos ámbitos de trabajo.

A Fausto Rea, estudiante de Ingeniería Ambiental, y a Celeny Herrera, estudiante de Ingeniería en Administración de Empresas, de la Universidad Politécnica Salesiana - Quito, por su asistencia técnica y administrativa.

\section{Referencias}

Baquero, F., R. Sierra, L. Ordóñez, M. Tipán, L. Espinosa, M. Rivera y P. Soria. 2004. La Vegetación de los Andes del Ecuador - Memoria explicativa de los mapas de vegetación: potencial y remanente a escala 1:250000 y del modelamiento predictivo con especies in- 
dicadoras. EcoCiencia/CESLA/Corporación EcoPar/MAG SIGAGRO/CDC-Jatun Sacha/División Geográfica - IGM. Quito.

Cáceres, L. 2001. Prioridades sobre cambio climático en el ecuador. En: Comité Nacional sobre el Clima, GEF-PNUD. Ministerio del Ambiente. Proyecto ECU/99/G31 - Cambio Climático. Fase II. Quito - Ecuador.

Cáceres, L., R. Mejía y G. Ontaneda. 1998. Evidencias del cambio climático. En: Cáceres, L. 2001. Prioridades sobre Cambio climático en el Ecuador. Comité Nacional sobre el Clima, GEF-PNUD. Ministerio del Ambiente. Proyecto ECU/99/G31 - Cambio Climático. Fase II. Quito - Ecuador.

Coloma-Santos, A. 2007a. Parque nacional cotopaxi. En: ECOLAP y MAE. 2007. Guía del Patrimonio de Áreas Naturales Protegidas del Ecuador. ECOFUND, FAN, DarwinNet, IGM. Quito, Ecuador.

Coloma-Santos, A. 2007b. Parque nacional llanganates. En: ECOLAP y MAE. 2007. Guía del Patrimonio de Áreas Naturales Protegidas del Ecuador. ECOFUND, FAN, DarwinNet, IGM. Quito, Ecuador.

Coloma-Santos, A. 2007c. Refugio de vida silvestre pasochoa. En: ECOLAP y MAE. 2007. Guía del Patrimonio de Áreas Naturales Protegidas del Ecuador. ECOFUND, FAN, DarwinNet, IGM. Quito, Ecuador.

Coloma-Santos, A. 2007d. Reserva ecológica los ilinizas. En: ECOLAP y MAE. 2007. Guía del Patrimonio de Áreas Naturales Protegidas del Ecuador. ECOFUND, FAN, DarwinNet, IGM. Quito, Ecuador.

Cuesta, F. y C. Chiriboga. 2010. Indicadores de evaluación del impacto del cambio climático sobre la biodiversidad de los países de la comunidad andina. En: Consorcio para el Desarrollo Sostenible de la Ecorregión Andina CONDESAN. IUCN - Comunidad Andina. 2010.

Delgado, T. 2008. Evolución de la diversidad vegetal en ecuador ante un escenario de cambio global. En: Memoria de Tesis Doctoral. Universidad Complutense de Madrid. Madrid.
ECOLAP y MAE. 2007. Guía del patrimonio de Áreas naturales protegidas del ecuador. En: ECOFUND, FAN, DarwinNet, IGM. Quito, Ecuador. Ecuador.

Gobierno de la República del Ecuador. 1981. Ley forestal y de conservacion de Áreas naturales y vida silvestre. En: Ley No. 74. RO/ 64 de 24 de Agosto de 1981. Quito.

INAMHI. 2009. El cambio climático en el ecuador. En: Revista del Instituto Nacional de Meteorología e Hidrología. Quito. Ecuador.

IPCC. 2000. Escenarios de emisiones. En: (Grupo Intergubernamental de Expertos sobre Cambio Climático. Informe especial del IPCC. Resumen para responsables de políticas. Grupo de Trabajo III. OMM-PNUMA.

Jiménez, M., B. Finegan, B. Herrera, P. Imbach y D. Delgado. 2009. Resiliencia de las zonas de vida de costa rica al cambio climático. En: 13th World Forestry Congress, Buenos Aires, Argentina.

MAE - Ministerio del Ambiente del Ecuador. 2007. Plan estratégico del sistema nacional de Áreas protegidas del ecuador 2007-2016. En: Informe Final de Consultoría. Proyecto GEF: Ecuador Sistema Nacional de Áreas Protegidas (SNAP-GEF). REGAL-ECOLEX. Quito.

MAE - Ministerio del Ambiente del Ecuador. 2008. Manejo sustentable de los bosques andinos. En: Dirección Nacional Forestal. MAE. Quito.

MAE - Ministerio del Ambiente del Ecuador. 2010. Registros de la subsecretaría de planificación ambiental. En: Dirección de información, Investigación y Educación Ambiental - DIEA. Quito.

Magaña, V., L. Gómez, C. Neri, R. Landa, C. León y V. Ávila. 2011. Medidas de adaptación al cambio climático en humedales del golfo de méxico (versión preliminar: síntesis). En: Banco Mundial - Instituto Nacional de Ecología. México.

Martínez, C. 2009-2010. Modificación espacial de los ecosistemas remanentes de los andes de ecuador por efecto del cambio climático. En: Tesis presentada Para optar por el título de 
Máster. Universidad Central del Ecuador y Universidad Internacional Menéndez Pelayo, España. Ecuador.

Palmberg-Lerche, C. 1998. Conservación de la diversidad biológica forestal y de los recursos genéticos forestales. Science, 279: 2060-2061.

Rivadeneira-Roura, C. y A. Coloma-Santos. 2007a. Geobotánica pululahua. En: En: ECOLAP y MAE. 2007. Guía del Patrimonio de Áreas Naturales Protegidas del Ecuador. ECOFUND, FAN, DarwinNet, IGM. Quito, Ecuador.

Rivadeneira-Roura, C. y A. Coloma-Santos. 2007b. Reserva ecológica el Ángel. En: En: ECOLAP y MAE, 2007. Guía del Patrimonio de Áreas Naturales Protegidas del Ecuador. ECOFUND, FAN, DarwinNet, IGM. Quito, Ecuador.

Rivera, J. 2007a. Parque nacional el cajas. En: En: ECOLAP y MAE. 2007. Guía del Patrimonio de Áreas Naturales Protegidas del Ecuador. ECOFUND, FAN, DarwinNet, IGM. Quito, Ecuador.

Rivera, J. 2007b. Parque nacional podocarpus. En: En: ECOLAP y MAE. 2007. Guía del Patrimonio de Áreas Naturales Protegidas del Ecuador. ECOFUND, FAN, DarwinNet, IGM. Quito, Ecuador.

Rivera, J. 2007c. Parque nacional sangay. En: En: ECOLAP y MAE. 2007. Guía del Patrimonio de Áreas Naturales Protegidas del Ecuador. ECOFUND, FAN, DarwinNet, IGM. Quito, Ecuador.

Rivera, J. 2007d. Área nacional de recreación el boliche. En: En: ECOLAP y MAE. 2007. Guía del Patrimonio de Áreas Naturales Protegidas del Ecuador. ECOFUND, FAN, DarwinNet, IGM. Quito, Ecuador.

Rivera, J. 2007e. Reserva de producción de fauna chimborazo. En: En: ECOLAP y MAE. 2007. Guía del Patrimonio de Áreas Naturales Protegidas del Ecuador. ECOFUND, FAN, DarwinNet, IGM. Quito, Ecuador, 2007.

Rivera, J. 2007f. Reserva de producción de fauna chimborazo. En: En: ECOLAP y MAE. 2007. Guía del Patrimonio de Áreas Naturales Protegidas del Ecuador. ECOFUND, FAN, DarwinNet, IGM. Quito, Ecuador.

Salas, P. 2009. Efectos del cambio climático sobre hábitats de aves endémicas en bosques de montaña de las yungas peruanas. En: Maestría de Ecología Aplicada. Universidad Nacional Agraria La Molina. Lima.

Secretaría General de la Comunidad Andina. 2008. Impacto del cambio climático en la comunidad andina. URL 〈www.comunidadandina.org.〉, mayo 2008, Lima 27, Perú.

Sierra, R. 1999. Propuesta preliminar de un sistema de clasificación de vegetación para el ecuador continenta. En: EcoCiencia - GEF. Quito.

Sánchez, O. y R. Benítez. 2009. Propuesta para el manejo y gestión del Área de conservación colambo-yacuri. En: Tesis de Maestría en Administración Ambiental. Universidad Nacional de Loja.

Yánez, P. 2009. La zona transicional páramobosque nublado: un elemento paisajístico móvil en el espacio tiempo. En: En La Granja Vol. 9. $\mathrm{N}^{\circ}$ 1., julio de 2009. Revista semestral de Ciencias de la Vida y Agropecuarias. Universidad Politécnica Salesiana. Ecuador. 